\title{
DESCOBRINDO O EGITO ANTIGO NA MODERNIDADE: A CONTRIBUIÇÃO DO ANTIQUARISTA GIOVANNI BELZONI (1816-1819)
}

Natascha de Andrade Eggers ${ }^{1}$

\begin{abstract}
Resumo
O principal objetivo do presente artigo é compreender a relação entre o Império Britânico e o Antigo Egito, a fim de demonstrar como os europeus, em especial os britânicos, utilizaram a imagem da civilização egípcia para a construção de uma identidade e memória nacional. Dessa forma, destaca-se o relevante papel que os viajantes antiquaristas tiveram neste processo, pois ao realizarem suas viagens deixavam registradas todas as suas impressões a respeito das culturas dos locais por onde passavam e, também, da cultura material que encontravam. Tais relatos eram constantemente lidos na Europa e utilizados como fonte de conhecimento, pois traduziam para o europeu o "outro" e relatavam suas interpretações a respeito do passado e presente de determinado local. Dessa forma, analiso o diário de viagem do antiquarista Giovanni Belzoni com a intenção de compreender como seu discurso pode ter contribuído para tal afirmação nacional, uma vez que este ajudou a construir uma grande coleção de peças egípcias do Museu Britânico, na Inglaterra.
\end{abstract}

\section{Palavras-chaves}

Giovanni Belzoni; Egito antigo; antiquarismo no Oriente, usos do passado, cultura material, identidade nacional.

\footnotetext{
${ }^{1}$ Programa de Pós-graduação em História - Mestrado. Bolsista CNPq. Universidade Federal do Paraná - Curitiba, PR, Brasil. e-mail: natascha.aeggers@gmail.com
} 


\begin{abstract}
The main objective of this article is to allow a better understanding of the relationship between the British Empire and Ancient Egypt, and show the ways through which European countries - and particularly Great Britain - used the image of the Egyptian civilization to build a national identity and memory. Antiquarians who travelled to search for exotic antiquities had a very important role in this process because they left in their notes a record of their thoughts about the cultures of the places they visited and about the material culture they found there. These memories and reports circulated in Europe and were regarded as a source of knowledge, since they offered a version of the unknown "other" and reported the travelers' interpretations of the past and present of foreign places. In this article I analyze the journal of one of these antiquarians, Giovanni Belzoni, in order to understand how his discourse may have corroborated the construction of a national identity, since he helped to form a large collection of Egyptian pieces of the British Museum, in England.
\end{abstract}

\title{
Keywords
}

Giovanni Belzoni; Ancient Egypt; antiquarianism in the Eastern World, uses of the past, material culture, national identity. 


\section{Introdução}

O século XIX na Europa foi marcado por uma constante busca, por parte dos recémcriados Estados nacionais, de uma historia ou memória coletiva que servisse de base para a constituição e afirmação da identidade nacional. Nesse contexto, disciplinas como a Arqueologia e a História, que estavam começando a se firmar cientificamente, passaram a ser utilizadas como aparato de base para legitimar as "origens" das Nações. São essas disciplinas que permitiram o conhecimento sobre as diferentes sociedades do espaço não-europeu, por meio de suas interpretações a respeito destes locais. Dessa forma, tais disciplinas não teriam surgido como discursos refletores da realidade, mas atravessadas de interesses políticos, econômicos e ideológicos, influenciados pelas rivalidades entre as Nações europeias que buscavam se afirmar enquanto Estados-Nação. Para tanto, a consolidação de uma história nacional e identidade singular se mostrou uma preocupação recorrente neste momento. Por isso, a constituição de espaços como os museus nacionais foram essenciais para este processo, pois continham em suas exposições artefatos que possibilitavam que essas Nações construíssem sua herança cultural.

As rivalidades entre alguns dos recém-criados países europeus os levaram a uma corrida expansionista e, também, ao interesse de buscar antiguidades em territórios desconhecidos, principalmente no Oriente, com a finalidade de aumentarem suas coleções nos museus. Nesse contexto, os viajantes antiquaristas tiveram papel relevante no processo de construção de memórias nacionais, pois transitavam entre diversos espaços, sendo mediadores entre estes lugares, no sentido de que levavam e traziam informações de um local a outro. Havia, entre estes viajantes, uma preocupação em descrever tudo que estava ao alcance de seus olhos e, por isso, muitos deles tinham a prática de escrever diários de viagens nos quais ficariam registrados detalhes das expedições e dos locais por onde passavam. Tais diários eram constantemente lidos na Europa e utilizados como fonte de conhecimento, pois traduziam para o europeu o "outro", o desconhecido, e relatavam suas interpretações a respeito do passado e presente de determinado local.

Partindo dessas informações, a intenção desse trabalho é discutir algumas interpretações que foram feitas na modernidade a respeito do Mundo Antigo, principalmente no que concerne à questão de como antiquaristas, administradores e políticos europeus usaram ativamente o Egito Antigo para ajudar a identificar e a definir suas próprias aspirações nacionais. Nesta pesquisa, o discurso a ser analisado será do italiano Giovanni Belzoni que viajou pelo Egito entre os anos de 1816 e 1819 e deixou registrado em seu diário de viagem todas as expedições que participou e, também, seu trabalho como antiquarista, em que acabou por reunir no Egito diversas 
peças que atualmente formam grande parte das coleções de artefatos egípcios que se encontram no Museu Britânico, na Inglaterra.

Para esta análise, busco embasamento teórico na perspectiva de "Usos do Passado", que surgiu no final do século XX a partir da preocupação em se repensar os significados da Antiguidade em tempos modernos e contemporâneos, a fim de compreender porque muitas nações direcionaram e direcionam seu olhar para a História Antiga com diferentes intencionalidades, buscando, muitas vezes, estabelecer ideias de herança cultural e continuidade histórica com o passado antigo. Influenciada pelas reflexões iniciadas por Martin Bernal a respeito de como o Mundo Antigo teria desempenhado um papel importante na definição da política moderna (Bernal, 2005: 224), tal perspectiva considera a História enquanto uma representação do passado, influenciada pela subjetividade de quem a escreve. Dessa forma, cada época seria influenciada pelos valores de seu presente e, a partir disso, resgataria no passado os aspectos que melhor convém e que atendem suas necessidades no momento.

Em seus trabalhos, Bernal se propôs a compreender como a Antiguidade teria se tornado um referencial para muitas nações, ajudando a construir novas identidades, discursos e interesses nacionalistas. Com isso, Bernal instigou os pesquisadores da área de História Antiga - historiadores e também arqueólogos - a repensarem os pressupostos teórico-metodológicos da disciplina, o que resultou numa nova serie de trabalhos, interpretações e reflexões sobre essas questões. Essa nova vertente de estudos vem ganhando força no campo de pesquisa da História Antiga atualmente, buscando uma leitura menos normativa e conservadora do passado, prezando por uma História mais problematizada (Funari, 2005, 119) e, por isso, cada vez mais historiadores e arqueólogos tem direcionado os seus esforços para o estudo das apropriações modernas e contemporâneas da Antiguidade.

O artigo está dividido em quatro partes: O Egito Antigo na Modernidade, em que será discutido o (re)descobrimento do Egito na modernidade, a presença de diversos viajantes nesta região e a consequente exploração de sua cultura material; Giovanni Belzoni e o antiquarismo no início do século XIX, que tratará do contexto de vida de Giovanni Battista Belzoni, e do meio antiquarista no Egito durante o século XIX; Reflexões sobre o Antigo e Moderno Egito: as viagens de Belzoni contadas à Europa, em que será apresentado seu diário de viagens, que contém os registros de suas descobertas e narrativas elaboradas ao longo de sua passagem pela terra dos faraós; por fim, $\mathrm{O}$ Egito e a construção da identidade nacional britânica, em que serão discutidos e problematizados os discursos de Belzoni a fim de compreender de que forma esses discursos abordam e delineiam a imagem do próprio britânico nesse contexto. 


\section{O Egito Antigo na Modernidade}

De acordo com a historiadora Natália Monseff Junqueira, o Egito Antigo exerce desde a antiguidade certo fascínio em outras sociedades e o interesse sobre sua cultura material não passou despercebido por diversas civilizações ao longo do tempo (Junqueira, 2008: 2). No entanto, foi durante o período da Renascença que se iniciou uma busca incessante pelas antiguidades egípcias, levando diversos viajantes a terem a terra dos faraós como rota de suas expedições. Até o século XX, o interesse pelo passado egípcio antigo estimulou diversos antiquaristas e, posteriormente arqueólogos, a se esforçarem em transportar boa parte da cultura material que encontravam para a Europa. Nesse sentido, objetos como papiros, pinturas, jóias, adornos, múmias e esculturas começaram a fazer parte de coleções particulares e, posteriormente, a compor coleções museológicas (David, R., 1999: 8). Segundo Rosalie David,

[...] como resultado do intenso interesse em adquirir antiguidades desde a Renascença, os colecionadores estrangeiros começaram a conduzir suas próprias escavações no Egito. Incrivelmente, muitos conseguiam autorização dos administradores turcos para remover artefatos de dentro das tumbas e arrancar decorações e inscrições das paredes dos templos; acelerando dessa forma a "caça ao tesouro", com escavadores de diferentes países que competiam para adquirir os artigos mais valiosos. Entretanto, o principal objetivo deste exercício era fornecer aos seus patrões ricos os objetos desejados muito mais do que auxiliar no avanço da Egiptologia. (David, R., 1999: 8).

Em fins do século XVIII e durante o século XIX, no entanto, o interesse pelo Egito Antigo atraiu olhares com intenções mais científicas, sendo as pesquisas amplamente incentivadas pelas nações, que estabeleceram no Egito seus cônsules. Como resultado, os diversos artefatos antigos foram expostos em museus nacionais, dentre eles o Museu Britânico e o Museu do Louvre. De acordo com David, dois acontecimentos teriam sido de extrema importância para o desenvolvimento de uma ciência que estudasse o passado egípcio: a expedição militar de Napoleão Bonaparte (1769-1821) ao Egito e, também, a decifração dos hieróglifos por Jean-François Champollion (1790-1832), que possibilitou que o conhecimento sobre o Egito se aprofundasse cada vez mais no Ocidente.

Com base nesse contexto é que se desenvolve a Egiptologia durante o século XIX, estudo específico das sociedades egípcias antigas por meio da escrita e da cultura material encontrada pelos arqueólogos e antiquaristas. De acordo com Jean Vercoutter, durante o século XIX o Egito é redescoberto em toda a Europa e, "de um dia para o outro, poder-se-ia dizer, sem exagero, que o Egito se torna moda. De 1802 a 1830, uma dezena de viajantes de grande valor, franceses, alemães, ingleses, suíços, vem conferir [...] as maravilhas egípcias" (Vercoutter, J. 2002: 54) 
Com o desenvolvimento da Egiptologia, a presença europeia tornou-se comum no nordeste africano e, consequentemente, a espoliação dos objetos produzidos pela antiga civilização que ali vivera. Nesse sentido, não somente antiquaristas, mas também intelectuais viajaram ao Egito, produzindo discursos a respeito da cultura material, dos povos, da paisagem que encontravam e, então, "as narrativas e os desenhos, frutos de suas peregrinações, contribuem para manter a fama crescente que o Egito então conheceu" (Vercoutter, J. 2002: 54). E, dessa maneira, tanto o Egito Antigo quanto o Egito Moderno eram abordados nesses discursos e imagens, que eram levados para a Europa e tidos como fonte de conhecimento a respeito desses locais.

As representações feitas sobre o passado e presente egípcio, no geral, enfatizavam as paisagens exóticas, os grandes monumentos e, também, as diferenças de costumes entre egípcios e europeus. O estranhamento e a narração da diferença nos remetem às discussões de François Hartog, em que o historiador afirma que "dizer o 'outro' é enunciá-lo como diferente - é enunciar que há dois termos, a e b, e que a não é b" (Hartog, F. 1999: 229). Segundo Hartog, o problema do narrador está em como representar de forma persuasiva o mundo que se conta, ou seja, o "outro", no mundo em que se conta. Para Hartog, a retórica de alteridade é nada menos que uma operação de tradução, que visa transportar o "outro" ao seu mundo por meio da narrativa:

Para traduzir a diferença, o viajante tem a sua disposição a figura da inversão, em que a alteridade se transcreve como um antipróprio. Não há mais a e b, mas simplesmente a e o inverso de a. O projeto do discurso não é mais do que falar do próprio. (Hartog, F. 1999: 229).

Dessa maneira, o Egito é traduzido à Europa com base nos valores e costumes europeus e, por isso, a diferença é um aspecto bastante recorrente nas narrativas de viagens. Por meio dessas narrativas é que os egípcios e suas antiguidades ficam conhecidos em vários lugares, portanto, poder-se-ia dizer que os diários de viagens contribuem para a formação de opiniões e de conhecimento a respeito do Egito - seja sobre seu passado ou presente. Seus autores constroem, por meio da narrativa, o lugar que se narra com base em suas interpretações e, muitas vezes, acabavam por consolidar uma determinada imagem do Egito na Europa: diversos viajantes descreveram o Egito como exótico, misterioso, com passado brilhante, porém muitas vezes como incapaz e inferior, não civilizado.

Na obra Orientalismo: o Oriente como invenção do Ocidente, Edward Said discute sobre a maneira como o Oriente foi traduzido e, até mesmo, inventado para e pelo Ocidente. Segundo Said, o Oriente sempre atraiu o interesse dos ocidentais, em especial dos europeus e, por isso, as maiores, mais antigas e mais ricas colônias europeias se encontram nesta parte do mundo. Além disso, o Oriente é, também, um rival cultural do Ocidente, uma de suas imagens mais profundas e mais recorrentes do 
"outro". Para o autor, o Oriente teria ajudado a definir a Europa por meio de sua imagem e culturas contrastantes. (Said, 1990: 27)

Nesse sentido, o discurso ocidental sobre o Oriente é denominado pelo autor de Orientalismo, e tal discurso estaria presente no imaginário ocidental desde o século XIX. No entanto, o Orientalismo teria diversos significados que se entrelaçam: seria, em primeiro lugar, uma forma de discursar sobre o Oriente que teria como fundamento o lugar especial que este ocupa na experiência ocidental europeia; seria uma disciplina acadêmica; o que um estudioso do Oriente faz; um estilo de reflexão baseada numa distinção ontológica e epistemológica feita entre Oriente e Ocidente; e, por fim, uma forma ocidental de obter controle, domínio e autoridade sobre o Oriente. Em suma, “Orientalismo [...] consiste numa rede de interesses inevitavelmente aplicados (e assim sempre envolvidos) em toda e qualquer ocasião em que essa entidade peculiar, o 'Oriente', é discutida" (Said, 1990: 30)

O Orientalismo é postulado sobre a exterioridade, isto é, sobre o fato de que o orientalista, poeta ou erudito, faz o Oriente falar, descreve o Oriente, esclarece seus mistérios por e para o Ocidente. Ele nunca está preocupado com o Oriente exceto como causa primeira do que diz. O que ele diz e escreve, em virtude do fato de ser dito ou escrito, pretende indicar que o Orientalismo está fora do Oriente, não só como fato existencial, mas também moral. O produto principal desta exterioridade é certamente a representação: [...] o Oriente é transformado, passando de uma alteridade muito distante e frequentemente ameaçadora para figuras que são relativamente familiares. (Said, 1990: 51)

Conforme Said, Orientalismo é um empreendimento cultural essencialmente britânico e francês, pois desde o século XIX até o fim da Segunda Guerra Mundial essas nações teriam dominado o Oriente, sendo as pioneiras em colonizar essa região. Nesse sentido, para Said, o Orientalismo é marcadamente um fato cultural e político, em que o Leste seria incorporado e generalizado por meio de um discurso ocidental. A cultura europeia ganhou força e identidade ao se contrastar com o Oriente e, a partir de suas reflexões sobre este local, o inventou, como uma forma de delimitar suas próprias características, sendo o Oriente um reflexo invertido ou uma oposição do Ocidente. Com isso, consolidam-se a hegemonia de ideias europeias sobre o Oriente, e que, consequentemente, afirmam a superioridade europeia sobre o atraso oriental.

Contudo, tal relação está longe de ser simplista, pois não se pode afirmar que o Oriente foi uma criação sem realidade correspondente. (Said, 1990: 32) De acordo com Said, seria incorreto acreditar que o Oriente foi criado como uma simples necessidade de imaginação, pois a relação entre Oriente e Ocidente é, acima de tudo, uma relação de poder, de dominação. “O oriente não foi orientalizado porque se descobriu como oriental, mas também porque poderia ser transformado em oriental" (Said, 1990: 32). 
Dessa forma, a interação entre Leste e Oeste se estabeleceria por meio de relações de dominação e poder, que buscariam a hegemonia ocidental sobre a oriental.

A partir dessas questões, percebemos que os recém-criados Estados Nacionais tiveram seus projetos de construção da Nação e de identidades fortemente influenciados pelo olhar que se direcionava para as culturas que eram contrastantes a eles. Nesse contexto, o Oriente e o discurso orientalista se fazem presentes, influenciando intelectuais, viajantes e até mesmo políticos a construírem suas reflexões sobre esta parte do mundo, no qual o Egito está inserido. Por meio de seus discursos, os viajantes europeus levam para o Ocidente suas impressões a respeito do Oriente, muitas vezes ressignificando a cultura que encontravam, sendo ela a egípcia antiga ou moderna. E é nesse contexto que se insere o viajante italiano Giovanni Belzoni, ao narrar o Egito antigo e moderno em seu diário de viagem, suas impressões e discursos sobre o Egito se tornam pertinentes para as reflexões que serão feitas no item seguinte.

\section{Giovanni Battista Belzoni e o Antiquarismo no início do Século XIX}

Giovanni Battista Belzoni nasceu na cidade italiana de Pádua, em 5 de novembro de 1778. De acordo com uma de suas biografias, elaborada por Ivor Noel Hume Belzoni era um homem bonito, muito alto e com uma força incomparável, aspectos que sempre aparecem nas descrições feitas por seus contemporâneos. (Hume, 2011: 6) A fim de estudar hidráulica, Belzoni se muda para Roma com 17 anos, contudo, nessa época a Europa estava em um período de tumulto político, principalmente por causa das ações das tropas de Napoleão em diferentes locais do continente, então, quando Roma é invadida pelos franceses Belzoni vai para Paris e depois para a Holanda, locais em que permanece por pouco tempo até sua mudança para a Inglaterra em 1803 (Hume, 2011). Em solo britânico Belzoni acaba por morar durante nove anos, se naturalizando. Para ganhar a vida, vendia jogos de água de sua própria invenção em feiras e, também, se apresentava com um grupo circense em várias cidades inglesas, inclusive no Sadler's Wells Theatre, em Londres. Aproveitando seu físico, o italiano atuava nos teatros como strongman, fazendo provas de força (Siliotti, 2007: 196).

Na Inglaterra, Belzoni conhece sua futura esposa, Sarah, que o acompanhará em suas viagens e expedições pela Europa e África. Em 1812, junto com sua esposa, decide sair da Inglaterra e inicia suas viagens por diversos locais, como Portugal, Espanha e Malta. Em 1814, quando chega em Malta, Belzoni conhece o capitão Ismail Gibraltar, emissário do vice-rei egípcio Mahomed Ali, que lhe convida para ir ao Egito por acreditar que seus conhecimentos de hidráulica poderiam ser úteis. Segundo Siliotti, naquela época o vice-rei egípcio estava empreendendo uma série de investimentos em 
questões agrícolas e de irrigação, buscando trazer para o Egito engenheiros e técnicos europeus que pudessem apresentar novas técnicas e conhecimentos (Siliotti, 2007: 164).

Acompanhado de sua mulher e de um empregado irlandês, no ano seguinte Belzoni vai ao Egito, onde trabalha durante dois anos para montar uma máquina hidráulica que se destinava à irrigação dos campos. (Vercoutter, 2002: 68). No intuito de enriquecer, Belzoni propunha que sua invenção substituísse a tradicional roda hidráulica e, então, resolve apresentá-la a Mahomed Ali que, imediatamente interessado, pede que a nova invenção seja testada em sua frente. Entretanto, no dia em que a máquina foi testada, um erro de funcionamento foi suficiente para convencer o vice-rei de que sua inovação não serviria. De acordo com Stanley Mayes (2010: 23), não se sabe ao exato se Belzoni tinha conhecimentos em hidráulica que fossem suficientes para que sua máquina funcionasse. Para o autor, quando Belzoni escreve seu diário de viagem, este já gozava de certa fama e, por isso, em suas narrativas, daria tanta ênfase para seus conhecimentos científicos, especialmente em hidráulica.

Com o fracasso de sua invenção, Belzoni fica sem dinheiro para se manter em terras egípcias, o que o faz pensar em deixar o local. No entanto, nessa mesma época Henry Salt, membro do conselho de administração do Museu Britânico, é nomeado cônsulgeral da Inglaterra no Egito e busca, a pedidos do diretor do Museu Britânico, Sir Joseph Bankes, constituir coleções de antiguidades. Ricos colecionadores também encomendam algumas peças a Salt. Em uma carta pública do Foreign Office destinada a Salt, é solicitado que ele "antecipe seus rivais franceses na coleta de materiais antigos" (Mayes, 2010: 23). Para isso, o cônsul britânico passa a contratar agentes que pudessem auxiliá-lo na busca por antiguidades egípcias, o que acaba interessando Belzoni.

À serviço do cônsul britânico e com financiamento, Belzoni viajou pelo Egito e regiões próximas entre os anos de 1816 e 1819 colecionando antiguidades e realizando importantes descobertas, as quais foram registradas em seu diário. Segundo Mayes, a primeira grande ação de Belzoni, enquanto antiquarista, foi a retirada do busto colossal de Ramsés II da cidade de Tebas e seu transporte para o Museu Britânico em Londres. Anteriormente, os franceses já haviam tentado remover o busto do templo de Karnak, mas não obtiveram sucesso, pois era quase impossível mover um bloco de pedra pesando entre 7 e 8 toneladas, transportá-lo por cima da areia fina e depois colocá-lo em um navio. Após a retirada do busto colossal de Ramsés II, o antiquarista passa os três anos seguintes viajando e fazendo outras importantes descobertas: abre e escava o templo de Abu Simbel, descobre tumbas reais no Vale dos Reis, abre a segunda pirâmide de Gizé, encontra a cidade perdida de "Berenice" e constitui grandes coleções de antiguidades egípcias, das quais muitas estão expostas atualmente em museus europeus. 
Em 1819, quando Belzoni volta para Londres, decide organizar uma exposição no Egyptian Hall de Piccadilly, com a finalidade de apresentar ao público as peças que havia reunido nos quatro anos de atividade no Egito. Após sua morte, a exposição de Belzoni foi levada para Paris, nos mesmos dias em que Champollion escrevia a Lettre à M. Dacier, na qual desvendava o mistério da escrita hieroglífica. (Siliotti, 2007: 175). Belzoni foi homenageado pelo Regency London por ser um grande viajante e, enquanto estrangeiro, foi aprovado e homenageado por sua devoção aos interesses britânicos (Mayes, 2010: 12). Belzoni morreu um ano depois, em 3 de novembro de 1823, aos 45 anos, em um pequeno povoado nas imediações do rio Benin, na África equatorial, onde havia se dirigido com a ideia de explorar a cidade de Tombuctu. No entanto, Belzoni deixou, com a publicação de seu diário, diversos registros de suas operações em viagens.

A obra Narrative of the Operations and recent discoveries within the pyramids, temples, tombs and excavations in Egypt and Nubia and of a Journey to the Coasts of the Red Sea, in search of the Ancient Berenice and another to the Oasis of Juppiter Ammon, de Giovanni Belzoni, foi publicada no ano de 1820, na cidade de Londres e é composta por 483 páginas divididas em três capítulos: 'First Journey', 'Second Journey' e 'Third Journey'. No primeiro capítulo, Belzoni narra a sua chegada ao Egito, suas primeiras dificuldades ao lidar com os povos locais, a apresentação de sua invenção hidráulica ao vice-rei egípcio, o seu envolvimento com o antiquarismo e com os cônsules europeus e, por fim, a operação de retirada e o transporte do busto Colossal de Ramsés II para a Inglaterra.

No segundo capítulo, aparecem descrições a respeito de suas passagens por Tebas e Luxor, suas descobertas de templos e tumbas no Vale dos Reis, encontro de múmias humanas e animais, sua visita às pirâmides de Gizé e a descoberta da entrada de uma delas. No terceiro capítulo Belzoni narra sua volta para Tebas e a preparação para a viagem ao Mar Vermelho, a descoberta da cidade perdida de Berenice, retirada do obelisco da ilha de Philae para Alexandria e, finalmente, a descrição da viagem para o Oásis de Ammon. A obra conta, ainda, com um capítulo extra que foi escrito pela mulher de Belzoni, Sarah, a respeito dos costumes das mulheres do Egito, da Núbia e da Síria: "Mrs. Belzoni's trifling account of the women of Egypt, Nubia, and Syria".

Com a finalidade de ilustrar suas descobertas em viagens, Belzoni publica, junto com o diário, um atlas com 44 desenhos em aquarela feitos pelo próprio autor durante suas viagens (Fortyfour Plates Illustrative of the Researches and Operations of Belzoni in Egypt and Nubia). No mesmo ano de sua publicação a obra de Belzoni foi traduzida para diversas línguas, chegando às mãos de diversos pesquisadores, como Howard Carter, o descobridor da tumba de Tutancâmon, que, quase um século após sua publicação, definiu-a como "um dos livros mais fascinantes entre todos os escritos sobre o Egito" (Siliotti, 2007: 162). 
No prefácio da obra, Belzoni deixa claras quais as razões que o teriam motivado a escrever sobre suas aventuras em terras não europeias:

Logo que cheguei à Europa, descobri diversos relatos errôneos sobre minhas operações e descobertas no Egito, o que pareceu ser minha obrigação publicar uma clara declaração de fatos [...] que talvez seja capaz de provar a verdade das minhas afirmações. (Belzoni, 1820: ix)

A preocupação de Belzoni em levar a "verdade" para a Europa se mostra presente ao longo de toda a obra, pois, segundo Stanley Mayes, Belzoni e o cônsul-geral da Inglaterra, Henry Salt, teriam se desentendido após algum tempo trabalhando juntos e, por isso, cada um tentava contar uma versão sobre o que acontecera durante esse tempo.

\section{Reflexões sobre o Antigo E Moderno Egito: as Viagens de Giovanni Belzoni Contadas à Europa}

Giovanni Belzoni, logo no prefácio de seu diário, deixa claro que a maior dificuldade encontrada ao longo de toda sua jornada por terras egípcias foi lidar com os povos que a habitavam. As reclamações do autor a respeito da cultura e do comportamento dos diferentes povos com que teve contato são recorrentes em sua obra e proporcionam, para o leitor, a imagem de um local completamente contrastante com a civilização que os europeus estão habituados. Como Belzoni passa muito tempo no Egito e em regiões próximas, ele conheceria a população local de forma mais profunda que outros europeus, o que, em sua opinião, o diferenciaria de um viajante comum, que acaba não convivendo um tempo suficiente com os orientais a ponto de conhecer "o caráter desses povos" (Belzoni, 1820: v).

Nenhum viajante jamais teve tais oportunidades de estudar os costumes dos nativos como foram oferecidas a mim, pois ninguém teve que lidar com eles de maneira tão peculiar. Minha constante ocupação era procurar antiguidades e isso me levou, nas diversas transações que tive, a observar o real caráter dos turcos, árabes, núbios, beduínos e tribos ababdy. Assim, eu era muito diferente de um viajante comum, que apenas faz suas observações sobre o país e suas antiguidades, ao invés de ter que persuadir essas pessoas ignorantes e supersticiosas para realizar uma tarefa dificil, nos trabalhos, com a qual eles estavam anteriormente totalmente desacostumados. (Belzoni, 1820: v).

Em muitas passagens de seu diário, notamos esse distanciamento que Belzoni faz entre os egípcios e os europeus. Ao chegar ao Egito, Belzoni conta sobre as dificuldades de estar em um local desconhecido sem saber falar a língua local, além de enfrentar

problemas como pragas e outras doenças que afetavam os estrangeiros. Na narrativa

Revista Heródoto. Unifesp. Guarulhos, v. 01, n. 01. Março, 2016. p. 91-112.

-101 - 
do italiano, os orientais aparecem como povos não confiáveis e que estão sempre dispostos a tirar vantagem de alguém. Conforme Belzoni, antes mesmo de sua viagem ao Egito já teria recebido alguns conselhos de europeus sobre o local: "[...] a precaução que nos foi dada era a de nunca dar crédito ao que um árabe diz" (Belzoni, 1820: 6), e tal afirmação se repete em muitas partes de sua obra. Além disso, os orientais aparecem aos olhos do viajante como incivilizados, primitivos e bastante agressivos. Muitas passagens do diário, portanto, são destinadas à descrição dos povos que habitavam o Egito moderno e à forma como tratavam os viajantes estrangeiros. Segundo Belzoni, "o leitor, talvez, ache minha narrativa minuciosa demais; mas eu imploro que observe que é somente dessa forma que o verdadeiro caráter desse povo pode ser conhecido" (Belzoni, 1820: 48).

Apesar do choque inicial de Belzoni com a cultura egípcia moderna, aos poucos o viajante vai se acostumando com o local e passa a observar mais suas paisagens, descrevendo-as e construindo em sua narrativa um Egito contemporâneo, que é caracterizado por suas construções antigas e monumentais, suas paisagens exóticas e pelo povo diferente. Nesse sentido, as cidades do Egito contemporâneo são, de certa forma, um contraponto para o Ocidente, a versão oposta do que as cidades europeias e sua civilização representavam. Ao chegar à cidade do Cairo, o viajante se depara com uma paisagem completamente distinta do que está acostumado e em suas descrições dá ênfase para aquilo que contrasta com a sua realidade: as ruas tumultuadas, as vestimentas das pessoas, a forma como conversam, o cheiro desagradável do local, a belíssima paisagem ao se olhar para longe do centro, as feiras, as mercadorias que são vendidas, as antiguidades, danças, entre outros aspectos. Em outros momentos, Belzoni ressalta a exuberância das paisagens, contrastantes com o tumulto e a sujeira das cidades. Ao descrever a vista das pirâmides a partir da cidade do Cairo, o viajante demonstra estar extasiado com tudo aquilo que encontra: "a visão distante das menores pirâmides ao sul marcava a extensão daquela vasta capital, enquanto o solene e infinito espetáculo do deserto a Oeste nos inspirou com reverência ao todo-poderoso criador" (Belzoni, 1820: 6).

Após alguns meses no Egito, Belzoni acaba tendo cada vez mais contato com os orientais, primeiro por causa seu projeto hidráulico e, depois, com o seu trabalho de antiquarista. $\mathrm{O}$ viajante afirma ter passado por muitas dificuldades ao se estabilizar e se relacionar com seus habitantes e tais problemas só teriam diminuído na medida em que foi ficando conhecido pelo povo. Belzoni critica os costumes dos nativos e descreve inúmeras histórias em que acaba se indispondo com estes, principalmente com os chefes locais, que muitas vezes tentavam impossibilitar seu trabalho como antiquarista, chegando a ameaçá-lo com armas ou agressões físicas: “Em um país onde respeito apenas é dado ao mais forte, vantagens sempre serão tiradas do mais fraco" (Belzoni, 1820: 47). 
Em seu diário, Belzoni faz uma constante comparação das civilizações europeias e egípcias, demonstrando sempre, e de diversas maneiras, os benefícios da presença dos europeus neste local e também sugerindo certa superioridade destes, principalmente em questões de negociação, honestidade e amizade. A influência da Europa no Egito é algo considerado positivo pelo viajante, principalmente por questões de desenvolvimento tecnológico e econômico e, por isso, Belzoni mostra certa admiração pelo vice-rei, por ser aberto a essas tecnologias e estar em constante busca por inovações: "o vice-rei parecia estar bem ciente dos benefícios que podem ser derivados do incentivo às artes da Europa em seu país, e até já colheu alguns frutos dessa relação" (Belzoni, 1820: 15).

Ao narrar sobre suas dificuldades em encontrar homens que pudessem trabalhar na retirada do busto de Memnon - Ramsés II - do templo de Karnak, o viajante mostra sua decepção ao conversar com o Cacheff, ou chefe local, que se recusa a oferecer seus homens para o trabalho. Com isso, Belzoni reafirma sua perspectiva, na qual os habitantes do Egito lidariam com outras pessoas somente a partir de seus próprios interesses. Porém, o viajante afirma que, ainda assim, há algumas exceções entre esses povos, como entre os europeus há também aqueles que se aproveitam de situações e pessoas. Essa comparação feita entre europeus e egípcios mostra que o viajante preestabelece características a essas pessoas, considerando que os europeus, em geral, além de mais civilizados seriam mais honestos do que os egípcios. Essa questão pode ser notada também em outra passagem do diário, em que Belzoni visita o templo de Edfu e, impressionado com a magnificência do local e das construções lamenta o estado de conservação do edifício e a quantidade de lixo a sua volta. Segundo o italiano, os árabes que o habitavam pouco se importavam com a beleza e antiguidade do templo.

No dia seguinte, eu fiz uma inspeção rápida no templo daquela cidade. Ele está muito sobrecarregado com lixo, e apenas o pórtico pode ser visto; mas a bela variedade e belas capitais em forma de colunas, bem como as figuras zodiacais no teto, anunciam que era um dos principais templos do Egito [...] e é uma grande pena que esses belos edifícios sejam habitados por árabes sujos e seu gado. (Belzoni, 1820: 56)

Ao pensarmos sobre essas questões e discursos contidos no diário, notamos que os diversos povos com quem Belzoni manteve contato no Egito são classificados e descritos ao Ocidente como povos providos de hábitos imorais, brutos e sem educação, seja pela forma como comem, dançam ou se relacionam. Seriam povos que não contariam com muita inteligência e racionalidade, a não ser que precisassem tirar vantagem de alguém ou alguma situação. Nesse sentido, os egípcios foram representados como um viajante europeu, nas condições e contexto de vida de Belzoni, os via. 
Em contrapartida, os europeus também eram classificados na narrativa de Belzoni e aparecem como representantes da civilização, providos de tecnologia e desenvolvimento e, por isso, o oriente era encarado com certa estranheza, ao ser contrastado com os hábitos e costumes ocidentais. Como afirmou Edward Said na obra Orientalismo, muitas vezes o Ocidente acaba adquirindo a importância de uma autoridade paternal em relação ao Oriente, capaz de guiá-lo ao caminho da civilização e evolução, uma vez que estava em um estágio avançado de desenvolvimento tecnológico e, também, moral. (Said, 1990: 42) A presença ocidental no Oriente, dessa forma, diversas vezes pode ser justificada pelas intervenções feitas com propósito evolutivo, que levariam a um desenvolvimento civilizacional. Dessa forma, o Ocidente conhece e sabe o que é bom para o Oriente "mais e melhor do que poderiam possivelmente saber eles próprios" (Said, 1990: 44).

Se quando Belzoni chega ao Egito, ele mostra estar completamente chocado com a cultura local e costumes de seus habitantes, por outro lado, ao ver a cultura material deixada pelos antigos egípcios, demonstra estar perplexo e maravilhado: "Para onde quer que os olhos se voltem, onde quer que a atenção seja fixada, tudo inspira respeito e veneração [...]" (Belzoni, 1820: 35). Não apenas os objetos antigos maravilhavam o viajante, mas também as paisagens exóticas, descritas em detalhes em seu diário, contadas ao mundo ocidental com muita fascinação. Nesse sentido, podemos perceber na narrativa de Belzoni a presença do deslumbre e encanto às maravilhas que encontra no Egito, sejam elas naturais ou construídas pelo homem no passado, que motivam o viajante a dar descrições detalhadas estabelecidas por seu olhar e que vão, aos poucos, delineando e construindo um passado egípcio glorioso repleto de monumentos e tesouros valiosos. Com isso, notamos que o olhar de Belzoni seleciona aquilo que é admirável, e com sua fascinação pelos grandes monumentos procura naquela antiga sociedade os indícios do apogeu de uma civilização desenvolvida.

Após conhecer uma das tumbas de Hermopolis, e com base em outros monumentos e peças vistas antes, Belzoni conclui que os egípcios antigos teriam sido um povo glorioso "Pelo que tenho visto das tumbas nessas montanhas, eu sou da opinião que Hermopolis foi habitada por grandes pessoas, e nada pode dar ideia mais justa da condição dos egípcios do que a qualidade das tumbas em que eram enterrados" (Belzoni, 1820: 30). À medida que Belzoni vai se envolvendo com o antiquarismo, passa a comparar a civilização egípcia antiga com os modernos egípcios, sendo sua principal preocupação em compreender como uma civilização tão grandiosa como a egípcia antiga, que produziu tantas maravilhas, teria se tornado aquela sociedade que Belzoni tinha diante de seus olhos, totalmente incivilizada, com hábitos imorais e que pouco se preocupava em preservar os resquícios de seu glorioso passado:

$\grave{A}$ Oeste do Nilo, o viajante ainda se encontra entre as maravilhas. Os templos de Gournou, Memnonium e Medinet Aboo, atestam a extensão da 
grande cidade deste lado. As incomparáveis figuras colossais nas planícies de Tebas, o número de tumbas escavadas nas rochas, [...] com suas pinturas, esculturas, múmias, sarcófagos, figuras, etc. são todos objetos dignos de admiração do viajante; que não deixará de se perguntar como uma nação, que uma vez foi tão grandiosa e que ergueu estes edifícios estupendos, poderia agora cair no esquecimento, e mesmo a sua linguagem e escrita se tornaram totalmente desconhecidas para nós. (Belzoni, 1820: 38).

Em outra passagem, Belzoni compara nitidamente o Egito moderno com o antigo, de forma a classificar este como superior àquele:

Ao olhar para um edificio de tal magnitude, acabamento e antiguidade, habitado por um povo selvagem, cujas cabanas estão presas nele, não muito diferente de ninhos de vespas, e para contrastar suas roupas sujas com estas imagens sagradas, que já foram tão altamente veneradas, faz sentir fortemente a diferença entre o antigo e o moderno estado do Egito. (Belzoni, 1820: 38 )

Ao analisarmos a passagem acima podemos pensar numa possível aproximação entre Egito Antigo e a Europa moderna que, mesmo que distantes temporalmente, se aproximam pelo grande nível de desenvolvimento e imponência destas civilizações. Por meio do discurso de Belzoni, quando é feita essa separação entre um presente egípcio considerado negativo e atrasado e um passado glorioso e deslumbrante, é justificada, de certa forma, a "missão civilizadora" que os europeus teriam para com os egípcios modernos. De certa forma, a presença europeia no Egito é legitimada no discurso do italiano, bem como a apropriação e espoliação das peças referentes ao seu passado antigo.

Na narrativa de Belzoni, é possível notar, também, que o viajante atribui valor às peças que encontra ao longo de sua viagem, exaltando as que ele considera mais valiosas, sugerindo que o melhor destino para esses artefatos fosse a Inglaterra. Nesse sentido, a invasão britânica no Egito teria a intenção de preservar tais antiguidades e dar a elas um destino, porém apenas as peças consideradas de valor estariam incluídas em tais planos. Como exemplo, pode-se perceber o entusiasmo de Belzoni ao ficar de frente com o Busto Colossal de Ramsés II - peça que foi retirada do Egito por ele e enviada ao Museu Britânico, onde até hoje se encontra: “Assim que eu entrei naquelas ruínas, meu primeiro pensamento foi examinar o busto colossal que eu teria que levar embora. Eu o encontrei perto dos restos de seu corpo e cadeira, com sua face para cima, aparentemente sorrindo para mim ao imaginar ser levado para a Inglaterra" (Belzoni, 1820: 39). Tal afirmação de Belzoni passa a sensação de que a cultura material por ele encontrada teria vontade própria e, neste caso, teria escolhido a Inglaterra como portavoz de seu passado. Temos, aqui, a sensação de uma missão enviada do passado aos países modernos, de um passado que fala e que precisa ser resgatado. 
Belzoni descreve, também, em seu diário sobre como os antiquaristas - incluído o próprio autor da obra - coletavam os artefatos, sem muitas preocupações científicas ou métodos para a preservação das peças, uma vez que a Arqueologia ainda não se constituía uma ciência. Conforme Rosalie David, o viajante tem sido muitas vezes comparado, em pesquisas históricas e biográficas, de forma negativa com cientistas e arqueólogos que estiveram no Egito posteriormente. (David, 1999: 16). Para a pesquisadora, tal comparação se mostra sem fundamentos, pois quando Belzoni fez suas descobertas no Egito, a Arqueologia começava a surgir na Europa e, portanto, seria anacrônico exigir que Belzoni utilizasse técnicas que estavam começando a ser estudadas. Ainda assim, na opinião de David, Belzoni "é inegavelmente uma inspiração e um prolífico escavador e teve um importante papel no desenvolvimento da área" (David, 1999: 16).

Muitas vezes, os escavadores acabavam destruindo algumas peças ou monumentos em favor de outras, apenas utilizando como critério o valor que acreditavam que as peças teriam. De acordo com as próprias palavras de Belzoni para que pudessem retirar o Busto de Ramsés II, tiveram que destruir algumas colunas do templo em que este se encontrava. Outro exemplo interessante é a forma como as múmias encontradas em uma tumba são tratadas pelo viajante, que pouco se preocupa em preservá-las, esmagando e quebrando diversas delas para que pudesse passar, ou as utilizando como apoio nas horas em que precisava descansar.

Segundo o historiador Moacir Elias Santos, Giovanni Belzoni teria vivido em uma época que é considerada "Era dos Antiquaristas", quando a Arqueologia estava no início de sua trajetória. Tal período era caracterizado pela intensa busca por artefatos antigos sem qualquer preocupação científica e, por isso, os métodos empregados na coleta dos objetos não tinham limites, muitas vezes causando danos aos artefatos encontrados. (SANTOS, M. 2012: 5). Com estes, os antiquaristas conseguiam vender grandes coleções para os museus europeus e colecionadores privados.

\section{O Egito e a Construção da Identidade Nacional Britânica}

Com base nas passagens do diário de Belzoni discutidas no item anterior, compreendemos diversas questões a respeito da importância dos viajantes e de seus relatos na legitimação identitária nacional europeia durante o século XIX. A representação do Oriente por meio dos discursos contidos nos diários de viagens e da cultura material proveniente das escavações, muitas vezes, possibilitava ser uma ferramenta de dominação cultural para as recém-formadas nações, que teriam como base o conhecimento e o poder (Junqueira, 2008: 13). A partir disso, o Oriente passa a 
ser capturado pelos relatos dos viajantes, em outras palavras, descrito e classificado pelo olhar ocidental, impregnado de intenções e ideologias. Posteriormente, esses relatos foram estudados e representados por meio dos estudos de Etnologia, Arqueologia, Antropologia e Filologia. O conhecimento das civilizações ocidentais acabou instigando estudos cada vez mais científicos sobre o passado, então, diversas disciplinas surgiram e desenvolveram nesse contexto.

Com base nessas questões, podemos considerar que construção de identidades europeias modernas teria tido como base o desenvolvimento da Arqueologia, já que esta possibilitava apresentar traços da cultura de diversos povos não europeus, por meio da representação europeia do "outro". (Junqueira, 2008: 14). É nesse contexto que também se desenvolve a Egiptologia durante o século XIX, estudo específico das sociedades egípcias antigas por meio da cultura material e escrita encontrada pelos arqueólogos e antiquaristas. Assim como a Arqueologia, a Egiptologia auxilia na representação do "outro", uma vez que muitos europeus tiveram seu olhar voltado para o Egito.

Tais questões nos remetem às discussões de Margarita Diaz-Andreu, a respeito da consolidação da Arqueologia como uma ciência profissional na Europa. Segundo a pesquisadora, o estudo do passado passa a ganhar um papel relevante na constituição e afirmação das Nações europeias, com o crescimento das políticas imperialistas e com o advento do nacionalismo, que levou diversos estados a financiarem a criação de um corpo profissional de arqueólogos ao longo do século XIX. Nesse contexto, a arqueologia passa a ser ministrada como disciplina nas universidades e diversos museus são criados para expor os objetos antigos que continham um passado digno de ser representado pelas recém-criadas nações (Diaz-Andreu, 2001: 17). Para a historiadora, os artefatos expostos nos museus justificavam a crença de que era dever das nações civilizadas de ajudar àquelas mais atrasadas a se desenvolverem e, dessa forma, a colonização também seria justificada (Diaz-Andreu, 2001: 17).

A expansão britânica e invasão do Egito no século XIX teriam facilitado o envio de expedições para o local, com a finalidade de coletar peças para a formação de coleções de antiguidades egípcias nos países europeus, época em que as escavações se intensificam, agora com bases mais científicas. Estudar e compreender esse movimento de expansão e interesses políticos permite um conhecimento mais crítico e amplo a respeito das interações entre passado e presente feitas na modernidade, além de sua contribuição para afirmações nacionais modernas por meio da utilização da imagem das sociedades e cultura material antigas. Possibilita notar que os interesses expansionistas não se restringiam apenas a interesses políticos e econômicos, mas também a aspirações ideológicas e culturais. Com isso, compreendemos que a política britânica no Egito auxilia na construção de uma noção de inferioridade dos egípcios na 
modernidade, e tal discurso a respeito do "outro" teria contribuído de forma significativa para a legitimação de seus interesses e da busca por afirmações nacionais.

Dessa forma, percebe-se, então, que Belzoni ao narrar e representar o egípcio - tanto antigo quanto moderno - em suas passagens acaba, paralelamente, construindo uma identidade europeia e, mais ainda, uma identidade britânica. Belzoni descreve em sua narrativa dois "Egitos", que são contados à Europa com base em ideologias e pensamentos ocidentais. De um lado, estaria o Antigo Egito, um lugar exótico e imponente, atraente pela grandiosidade de seus monumentos e cultura material, provenientes de um passado remoto. Por outro lado, estaria o Egito Moderno habitado por árabes e muçulmanos com costumes imorais e corrompidos, representando um papel de antagonista em relação ao europeu, que buscaria sempre afirmar a sua superioridade. Sendo assim, o discurso de Belzoni acaba justificando a invasão europeia e inglesa no Egito, que teria a intenção de levar a civilização a esses povos, preservar seu passado glorioso por meio de sua cultura material e, por fim, ao comparar europeus e egípcios, auxiliar na instituição de uma identidade completamente oposta às características egípcias.

Apesar do deslumbre de Belzoni pela terra dos faraós, por sua antiguidade e por seus esplendores monumentais e arquitetônicos, o viajante o desvaloriza em sua contemporaneidade. O viajante traça uma clara distinção entre "nós", civilizados ocidentais; e "eles", bárbaros orientais, reforçando, desta forma, uma identidade europeia e, como se considera britânico, também inglesa. Neste contexto, percebemos que o Egito é descrito por Belzoni não como realmente é, mas como foi visto e classificado pelo e para o europeu ou, como diria Edward Said, "não um oriente como ele é, mas o Oriente como foi orientalizado" (Said, 1999: 155). Além disso, ao descrever e diferenciar o moderno Egito de seu passado, o viajante faz uma aproximação entre Egito Antigo e a Europa moderna em seu discurso, destacando que tais civilizações tinham muito em comum por seu nível de desenvolvimento e grandiosidade. Tal pensamento poderia levar muitos europeus a acreditarem e se sentirem mais donos do passado egípcio do que os próprios egípcios que ali viviam durante o século XIX e, por isso, a pilhagem e espoliação da cultura material aconteceriam de forma indistinta. Dessa forma, as narrativas de Belzoni auxiliam na formação de uma identidade britânica no sentido de que contribuiriam para a disseminação da imagem buscada para a nação que estava se formando: uma nação civilizada e evoluída, diferente da forma primitiva em que era conduzida a vida no Egito. 


\section{Considerações Finais}

Ao analisarmos algumas passagens do diário, percebemos que Belzoni justifica, em seu discurso, a presença europeia no Egito, em especial a inglesa, o que pode ser percebido de duas maneiras: em primeiro lugar, pela forma como Belzoni se refere aos povos nativos como povos sem civilização, passando a ideia de uma superioridade dos europeus, em que estes estariam levando a civilização aos árabes, além de resgatar e conservar seu passado egípcio. Suas percepções em relação ao Egito moderno estavam muito próximas daquelas oriundas do discurso orientalista, com a intenção de classificar e descrever o Oriente para o Ocidente. Após o contato dos europeus com os egípcios modernos, o olhar e o discurso do viajante destacam que o Oriente se torna o oposto do europeu; sendo um local que possibilita a comparação da cultura europeia com outras diferentes culturas e a afirmação de sua suposta superioridade. Nesse sentido, o Oriente foi observado por Belzoni como um espelho invertido, um contraponto daquilo que o viajante, como ocidental e europeu, almejava para sua própria representação e identidade.

Em segundo lugar, ao interpretar a cultura material egípcia antiga que encontra ao longo de sua viagem, Belzoni justifica a presença europeia no Egito, além de atribuir valor às peças e exaltar as que considerava mais valiosas, sugerindo que o melhor destino para estes artefatos fosse a Inglaterra. Como resultado dessa dominação, ocorre a pilhagem da cultura material e, também, de riquezas das sociedades orientais, como no caso da cultura material egípcia antiga, que acabava sendo vista como propriedade dos invasores europeus, que removiam tais artefatos para a Europa para compor os acervos particulares e dos museus nacionais.

Sendo assim, esta pesquisa nos permitiu perceber que a conservação dos artefatos do Antigo Egito contribuiu para que fosse criada uma ideia de herança cultural, que ao mesmo tempo em que aproximava grandes civilizações - europeia moderna e egípcia antiga - pela grandiosidade de seus feitos e cultura, as afastava - moderno Egito da civilização ocidental -, enfatizando que a terra dos faraós, no estado de selvageria que se encontrava no século XIX, habitado por árabes e muçulmanos, não teria condições de conservar um passado imponente que, no sentido de civilização e desenvolvimento, tinha muito mais a ver com o Ocidente.

Dessa maneira, percebemos como a construção do passado, na obra de Belzoni, está ligada com aspectos recorrentes da época em que o viajante escreve e, portanto, questões de raça e etnicidade se mostram presentes em toda a sua narrativa. Estudar e problematizar tais questões significa contextualizar e desconstruir preconceitos arraigados nos discursos europeus oitocentistas, pois muitas vezes essas construções são retomadas e propagadas por diferentes épocas. Além de permitir um conhecimento 
mais crítico a respeito do passado estudado - Egito Antigo e Moderno -, rever essas representações do passado se mostra de suma importância, também, para debates atuais sobre racismo e etnicidade, possibilitando recolocar tal civilização num contexto mais africano, que muitas vezes é deixado no esquecimento.

\section{Referências}

\section{Corpus Documental}

BELZONI, G. B. Narrative of the operations and recent discoveries within the pyramids, temples, tombs, and excavations, in Egypt and Nubia. London: printed by Thomas Davison, 1820.

\section{Bibliografia}

BERNAL, M. “A imagem da Grécia antiga como uma ferramenta para o colonialismo e para a hegemonia européia", in: Repensando o mundo antigo - Martin Bernal, Luciano Canfora e Laurent Olivier (Funari, P.P.A. - org). Textos Didáticos $\mathrm{n}^{\circ}$ 49, IFCH/UNICAMP, 2005. 119-128, 1994. Traduzido por Fábio Adriano Hering e revisado por Pedro Paulo A. Funari.

BURKE, Peter. A Escola dos Annales (1929-1989): a Revolução Francesa da historiografia. São Paulo: Fundação Editora UNESP, 1997.

. Peter (Org.). O que é História Cultural? Rio de Janeiro: Jorge Zahar Ed., 2005

DAVID, R. Handbook to life in Ancient Egypt. New York: Oxford University Press, 1999.

DIAZ-ANDREU, M. Nacionalismo e Arqueologia: O contexto político da nossa disciplina. Revista do Museu de Arqueologia e Etnologia, São Paulo, 11: 3-20, 2001.

FONTANA, Josep. Historicismo e Nacionalismo. In: A História dos Homens. Bauru. Edusc, 2004

FUNARI, Pedro Paulo. Arqueologia. São Paulo: Contexto, 2003.

FUNARI, P. P A.; RAGO, M. Subjetividades antigas e modernas. São Paulo: Annablume, 2008. 
. Pedro Paulo A.; SILVA, Glaydson José. Teoria da História. São Paulo: Brasiliense, 2008.

. Pedro Paulo A. "Guerra do Peloponeso". In: MAGNOLI, Demétrio. História das guerras. São Paulo: Contexto, 2006, p. 19-45.

GARRAFFONI, R. S.; STOIANI, R. Escavar o passado, (re)descobrir o presente: os usos simbólicos da Antiguidade clássica por Napoleão Bonaparte. Revista de História da

GARRAFFONI, R.S., "Guerras Púnicas”, in: História das Guerras (Magnoli, D., org.), Editora Contexto, S.P., 2006, p. 47-75. Arte e Arqueologia, Campinas, nº 06, Dez. 2006, p. 69-82.

HARTOG, François. O espelho de Heródoto. Belo Horizonte: Ed. UFMG, 1999.

HINGLEY, R. O imperialismo Romano: novas perspectivas a partir da Bretanha, Annablume/Fapesp, 2010.

HUME, Ivor Noel. Belzoni: the giant archaeologists love to hate. Virginia. University of Virginia Press. 2011.

JENKINS, Keith. A História repensada. Tradução de Mario Vilela. Revisão Técnica de Margareth Rago. São Paulo, Contexto, 2001.

JUNQUEIRA, N. M. Uma viagem ao antigo Egito: a relação entre presente e passado na narrativa de bordo de Gustave Flaubert. História. Questões e Debates, v. 48/49, 2008, p. 01-20.

MAYES. S. The Great Belzoni: The circus strongman who discovered Egypt's treasures. Tauris Park Paperbacks. London, 2010, p. 23 e 107-109.

OLIVIER, Laurent. As origens da arqueologia francesa, in Repensando o Mundo Antigo. Trad. Glaydson José da Silva. Textos didáticos n. 49, IFCH/UNICAMP, 2003.

RAGO, M. A história repensada com ousadia. In: JENKINS, K. Repensando a História. São Paulo: Editora Contexto, 2005, p. 11.

L. M. A "nova" historiografia brasileira. Anos 90 (UFRGS), Porto Alegre, v. 11, p. 73-97, 1999.

REIS, J. J. "Introdução". Identidades do Brasil: de Varnhagen a FHC. Rio de Janeiro: Editora FGV, 2006.

SAID, E. Orientalismo: o Oriente como invenção do Ocidente. São Paulo: Companhia das Letras, 1990.

Revista Heródoto. Unifesp. Guarulhos, v. 01, n. 01. Março, 2016. p. 91-112. 
SANTOS, Moacir E. Das Necrópoles Egípcias para a Quinta da Boa Vista: Um Estudo das Partes de Múmias do Museu Nacional. Revista Mundo Antigo - Ano I - Volume Junho - 2012.

SILIOTTI, A. Primeiros descobridores: a descoberta do antigo Egito. Barcelona: Folio, 2007.

VERCOUTTER, J. Em busca do Egito esquecido. Rio de Janeiro: Objetiva, 2002. Pg. 54. 